\title{
O PEQUI E OS SABERES LOCAIS DOS CAMPONESES DO SERTÃO MINEIRO: primeiros apontamentos ${ }^{*}$
}

\author{
PEQUI AND THE KNOW PLACES OF THE PEASANTS OF THE \\ MINEIRO BACKWOODS: first notes
}

\section{PEQUI Y EL CONOCIMIENTO LOCAL DE LOS CAMPESINOS DE LA SERTÃO MINEIRO: las primeras notas}

\author{
Marcos Nicolau Santos da Silva \\ Instituto de Geociências - Universidade Federal de Minas Gerais \\ Mestre em Geografia pela Universidade Federal de Minas Gerais \\ Membro do Terra \& Sociedade - Núcleo de Estudos em Geografia Agrária, Agricultura Familiar e \\ Cultura Camponesa. Av. Antônio Carlos, nº 6.627, Pampulha, Belo Horizonte - MG. CEP: 31.270-901 \\ E-mail: marcos.nicolau@yahoo.com.br
}

\begin{abstract}
Resumo
Este trabalho apresenta uma parte dos primeiros resultados da pesquisa de mestrado do referido autor, realizada em comunidades rurais dos municípios de Campo Azul, Japonvar e Minas Novas, sendo os dois primeiros pertencentes à área geográfica do Norte de Minas Gerais e o último localizado no Vale do Jequitinhonha. O objetivo central é analisar as estratégias agroextrativistas que complementam a agricultura camponesa dos Cerrados, enfatizando os saberes locais dos sujeitos que usam o pequi (Caryocar brasiliense Camb.) como potencial econômico. Nos locais estudados, o próprio valor econômico do pequi também tem um significado cultural que se manifesta, entre outros, nos saberes acumulados pelos camponeses e na sua relação com a natureza dos Cerrados. As etapas de realização da pesquisa ocorreram entre julho de 2009 e julho de 2010, envolvendo inicialmente visitas prévias nas áreas de estudo para escolha e identificação das mesmas e de algumas famílias rurais e, posteriormente, o trabalho de campo definitivo. Os recursos utilizados na pesquisa foram entrevistas dirigidas semi-estruturadas e gravações de áudio com famílias camponesas. A amostragem é do tipo aleatória, em que foram escolhidas 15 famílias para serem entrevistadas em cada território de estudo, totalizando 45 entrevistas. A abordagem metodológica prioritária é a qualitativa.
\end{abstract}

Palavras-chave: Pequi, sertão, camponeses, saberes locais.

\footnotetext{
" Trabalho apresentado em formato de Mesa Redonda durante o Simpósio Internacional sobre Saberes Tradicionais, Biodiversidade, Biotecnologia e Dinâmicas Territoriais - SINBIOTEK, realizado nos dias 3, 4 e 5 de novembro de 2010 na UFG. O mesmo faz parte de pesquisas desenvolvidas junto ao grupo de pesquisa Terra \& Sociedade e vinculada ao projeto intitulado: "Mapeamento e análise das estratégias de reprodução social complementares da agricultura camponesa no recorte territorial de Minas Novas, Capelinha e Chapada do Norte - Vale do Jequitinhonha", financiado pela Fundação de Amparo à Pesquisa do Estado de Minas Gerais.
} 


\begin{abstract}
This work shows a part of the first results of the research of the referred author's master's degree accomplished in rural communities of the township of Campo Azul, Japonvar and Minas Novas, being the two first belonging to the geographical area of the Norte of Minas Gerais and the last located in Vale of Jequitinhonha. The central objective is to analyze the strategies agroextrativistas that complement the peasant agriculture of the Savannahs, emphasizing them local knowledge of the subjects that use the pequi (Caryocar brasiliense Camb.) as economical potential. In the studied places, the own economical value of the pequi also has been a cultural meaning that it shows, among other, in the knowledge accumulated for the peasants and in his relationship with the nature of the Savannahs. The stages of accomplishment of the research happened between July 2009 until July 2010, involving visits opinion polls initially in the study areas for choice and identification of the same ones and of some rural families and, later, the work of definitive field. The resources used in the research were interviews semi-structured and audio recordings with peasant families. Sampling is kind of random, were chosen 15 families to be interviewed in each territory of study, a total of 45 interviews. The priority methodological approach is the qualitative.
\end{abstract}

Keywords: Pequi, backwoods, peasants, know places.

\title{
Resumen
}

Este artículo presenta una parte de los primeros resultados de la investigación de maestría del autor, celebrada en las comunidades rurales de los municipios de Campo Azul, Japonvar y Minas Novas, con los dos primeros pertenecen a la zona geográfica del Norte de Minas Gerais y el último situado en Vale do Jequitinhonha. El objetivo principal es analizar las estrategias agroextractivist que complementan la agricultura campesina del Cerrados, con énfasis en el conocimiento local de los sujetos que utilizan pequi (Caryocar brasiliense Camb.) como potencial económico. En los lugares estudiados, el propio valor económico de pequi también tiene un significado cultural que se manifiesta, entre otros, en los conocimientos acumulados por los campesinos y su relación con la naturaleza del Cerrado. Los pasos de la investigación se llevó a cabo entre julio de 2009 y julio de 2010, inicialmente con visitas anteriores en las áreas de estudio para elegir y la identificación de los mismos y las familias rurales, y más tarde, el trabajo de campo final. Los recursos utilizados en la investigación fueron entrevistas semi-estructuradas y grabaciones de audio con las familias campesinas. El muestreo es de tipo aleatorio, en el que fueron seleccionadas 15 familias para ser entrevistadas en cada territorio de estudio, un total de 45 entrevistas. El enfoque metodológico es cualitativo prioridad.

Palabras clave: Pequi, sertão, los campesinos, el conocimiento local.

\section{Introdução}

O pequi (Caryocar brasiliense Camb.) e o pequizeiro são, respectivamente, o fruto e a árvore com grande abundância nos Cerrados brasileiros. De diversos valores: econômico, cultural, ecológico, gastronômico e medicinal, o pequi tem grande 
importância para suas populações quer seja no campo, quer seja na cidade. São nos Cerrados que os sertanejos conhecem profundamente a dinâmica de vida junto com o pequi, resultado de uma longa experiência de relação intrínseca com a natureza.

Estamos chamando de campesinato sertanejo o modo de vida dos camponeses que vivem há muito tempo em comunhão com os recursos naturais dos Cerrados. $\mathrm{O}$ campesinato sertanejo contempla tudo aquilo que é produzido indiretamente na terra do sertão, plantado e colhido, mais os recursos naturais dos Cerrados apropriados diretamente, tal como o pequi. O campesinato sertanejo se reproduz em todos os diversos ambientes dos Cerrados: veredas, chapadas, vazantes, grotas, cerradões, cerrado propriamente dito, matas galerias. Ele contempla diversos povos que vivem de acordo com os seus respectivos ambientes: vazanteiros, barranqueiros, chapadeiros, geraizeiros, veredeiros, caatingueiros, extrativistas, quilombolas, índios, camponeses, quebradeiras de coco etc. A marca desse campesinato é a sua própria diversidade.

Neste trabalho, estamos analisando o pequi como uma estratégia extrativista da agricultura camponesa, no qual buscamos destacar os saberes locais dos camponeses em comunidades rurais dos Cerrados dos municípios de Campo Azul e Japonvar, no Norte de Minas Gerais, e em Minas Novas, no Alto Vale Jequitinhonha.

O artigo está organizado, além dessa introdução e das considerações finais, em quatro partes. A primeira apresenta os aspectos metodológicos e a área de pesquisa de forma mais detalhada; a segunda busca analisar de forma mais teórica a formação do campesinato no sertão de Minas Gerais; na sequência procuramos mostrar algumas considerações acerca do que estamos chamando de campesinato sertanejo; por fim, apresentamos os principais saberes locais apontados pelos camponeses sobre o pequi.

\section{Aspectos metodológicos e área da pesquisa}

A pesquisa é de cunho descritiva e experimental, pois estamos utilizando métodos de descrição e observação associados ao levantamento de campo. Duas abordagens foram utilizadas, mas estamos priorizando, neste artigo, apenas a qualitativa, sendo a obtenção de dados feita através de entrevistas semi-estruturadas que nos permitem interpretar e refletir sobre o modo de vida das famílias camponesas, seus aspectos culturais, econômicos e sua relação com a natureza no sertão do Norte de 
Minas Gerais e do Vale do Jequitinhonha. Além disso, algumas entrevistas foram gravadas em áudio e transcritas para a aquisição de uma melhor riqueza de detalhes.

As áreas de estudo foram: as comunidades rurais Cachoeira do Fanado e Cachoeira da Lagoa, ambas no município de Minas Novas, no Alto Vale do Jequitinhonha; a comunidade rural Cabeceiras do Mangaí, em Japonvar; e, no caso do município de Campo Azul, fizemos entrevistas aleatórias na Vila São José e em outras quatro localidades rurais próximas. Em Campo Azul, as entrevistas foram realizadas em várias localidades rurais, pelo fato de haver uma distância maior entre as propriedades dos camponeses extrativistas de pequi, além, também, da maior dimensão das propriedades rurais, o que inviabilizou a concentração das entrevistas em uma ou duas comunidades rurais. Japonvar e Campo Azul situam-se na mesorregião geográfica do Norte de Minas Gerais.

A amostragem escolhida foi a aleatória simples por nos oferecer uma maior facilidade de seleção das unidades camponesas a serem estudadas, já que nem todas as famílias eram compostas por agricultores extrativistas de pequi.

Realizamos visitas de campo prévias para reconhecimento das áreas de estudo e de alguns sujeitos da pesquisa em Minas Novas, no mês de julho de 2009; em Japonvar e Campo Azul, no mês de outubro de 2009 e janeiro de 2010, respectivamente. Posteriormente, foram feitos os trabalhos de campo definitivos, no mês de abril de 2010, em Japonvar e Minas Novas, e, no mês de julho deste mesmo ano, em Campo Azul. Nas comunidades rurais pesquisadas, foram feitas 15 entrevistas em cada município, totalizando 45 famílias.

Como material de auxílio à coleta de dados foi utilizado o formulário de entrevista que contou com a presença desse pesquisador para o seu devido preenchimento. Além disso, utilizamos as gravações das conversas e as respostas às entrevistas a fim de obter maior riqueza de detalhes através do uso de fontes orais.

Cabe salientar que os relatos dos camponeses foram transcritos e mantidos na linguagem coloquial, fazendo-se o mínimo de correções, com o objetivo de manter-se a originalidade, sem, portanto, ter a intenção de ridicularizar os sujeitos da pesquisa. Por conseguinte, não revelamos a identificação dos camponeses entrevistados, apenas destacamos o sexo, idade e a localidade de residência dos mesmos.

Para complementar, a propriedade de cada família camponesa visitada foi 
pontuada por GPS (Global Positioning System), para depois serem elaborados os mapas de cada localidade identificando as unidades amostrais da pesquisa. Para esse artigo, somente elaboramos um mapa geral que identifica os municípios estudados.

No mapa abaixo (FIG. 1), destacamos apenas para efeito de visualização os municípios de Japonvar e Campo Azul na mesorregião Norte de Minas Gerais, sendo o primeiro mais ao norte e o segundo mais ao sul. No Alto Vale Jequitinhonha, temos o município de Minas Novas.

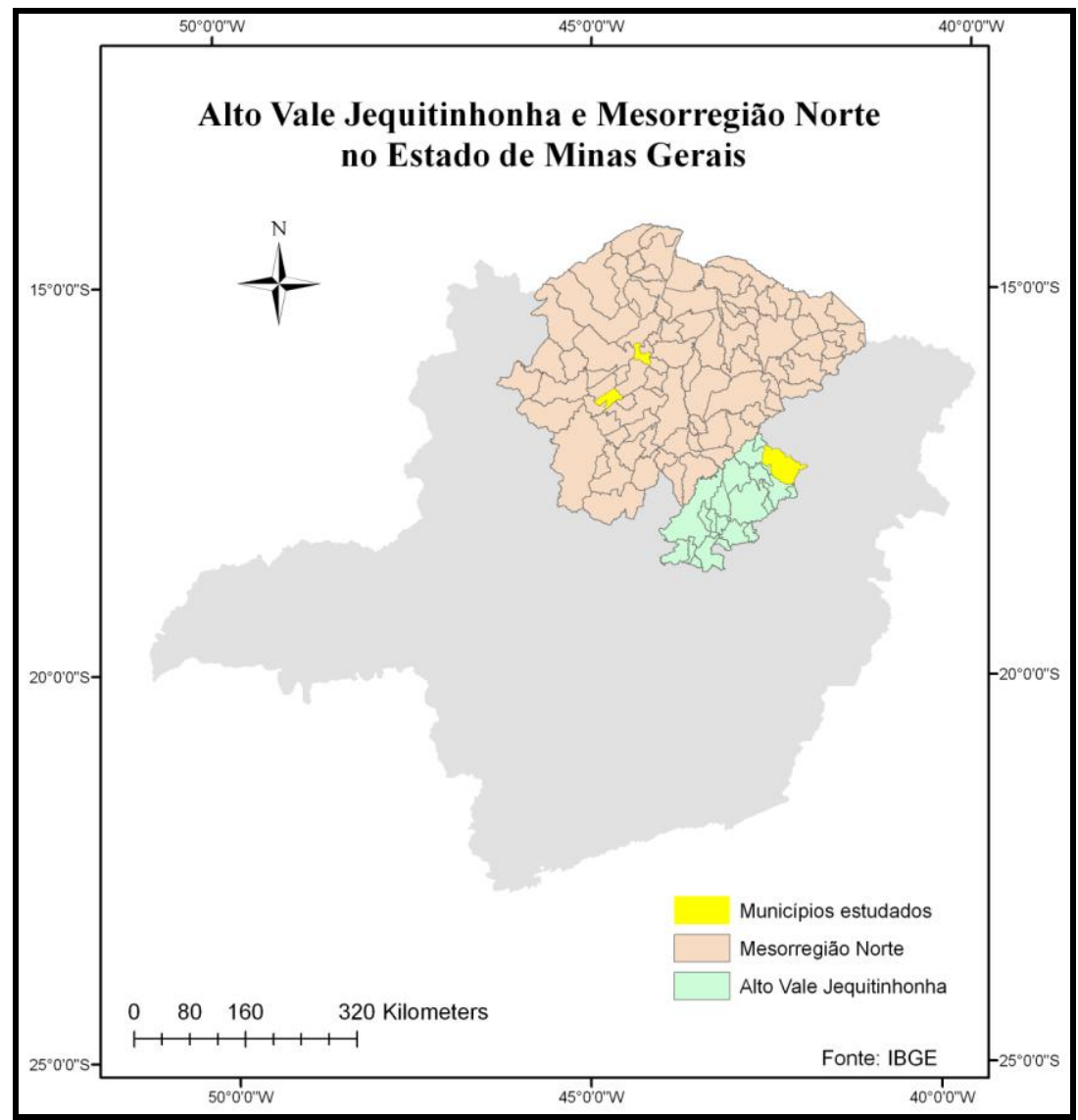

FIGURA 1 - MAPA: Localização dos municípios estudados na Mesorregião Norte e no Alto Vale Jequitinhonha, no estado de Minas Gerais.

Autor: SILVA, M. N. S.; 2010.

\section{Reflexões sobre o campesinato do sertão mineiro}

O campesinato e o camponês, apesar de serem termos, categorias e/ou conceitos já bastante conhecidos no meio acadêmico, ainda possuem conotações que causam certa estranheza. Também são, não raras vezes, acrescidos de uma grande polissemia, 
tornando uma tarefa cada vez mais difícil defini-los. Chegamos à conclusão de que a complexidade que envolve o universo interno e externo do campesinato é muito grande, e não é possível analisar uma determinada realidade social do campesinato de forma estanque. Faz-se imprescindível considerar a dinâmica interna e externa do campesinato, bem como as constantes mudanças e contextos nos quais ele está inserido. Por isso, o conceito de campesinato deve ser analisado de acordo com as características mais gerais que lhe aplicam e com a realidade específica de cada grupo estudado, não as tornando camisas-de-força, mas como ferramentas teóricas que procuram dar conta dessa complexidade.

Desde o final do século XIX, foram produzidos trabalhos que se tornaram clássicos da literatura sobre o campesinato, apoiados, sobretudo, no forte viés do materialismo histórico vigente no período em questão. Os principais trabalhos são os de Lenin, Kautsky e Chayanov. Posteriormente, o campesinato como temática reaparece pela década de 1970 e ressurge novamente dentro das concepções do materialismo histórico. Não vamos nos deter à teorização clássica acerca do campesinato, uma vez que esta se encontra bastante debatida desde os autores mencionados acima até aqueles mais contemporâneos.

Alguns autores defendem que a formação de um campesinato no Brasil é resultado dos resquícios feudais que chegaram ao campo no país, principalmente, via colonização portuguesa (GUIMARÃES, 1989). Já outros autores interpretam que o campesinato brasileiro não possui nenhum resquício do feudalismo europeu e, portanto, é resultante de um processo histórico de formação, criação e recriação do camponês (GORENDER, 1994). Um fato é certo, não se tem no país um camponês clássico, como aquele que surgiu na Europa, mas existe um camponês que se formou a partir daqueles que já viviam na e da terra, da importação do negro escravo africano, do imigrante expropriado dos meios de produção em seus países e da mistura desses povos. Há uma enorme variação de camponeses no país, em diversas regiões, e cada um deles guarda as relações de produção e reprodução com a terra, mesmo quando não possui o domínio sobre ela. O que importa é que tais camponeses estão existindo, resistindo e, muitas vezes, até reexistindo, sempre na luta pela propriedade da terra e pela sua manutenção nela.

O camponês no Brasil, assim como o camponês clássico ou de outros países, além 
de manter relações indiretas com a terra - plantio, cultivo e colheita - ainda extrai, diretamente, tudo que ela produz: argila, madeira, frutos nativos, palhas e demais fibras para artesanato e confecção de utensílios domésticos etc. Assim como foi registrado por Kautsky (1972), a família camponesa dispunha ou se bastava daquilo que era necessário à sua subsistência (não se limita o termo subsistência apenas ao que é produzido para o consumo, mas compreende também a geração de um excedente). Havia, portanto, uma relação intrínseca com a natureza.

Durante os dois primeiros séculos depois da colonização, foi a exportação de açúcar a principal atividade, porém havia também o cultivo do tabaco o qual era essencial para manter o tráfico negreiro, apesar de o plantador não possuir o mesmo prestígio e poder que o senhor de engenho. A pecuária bovina, por sua vez, foi outra atividade importante que se desenvolveu no Nordeste, pois, além de o gado ser importante no trato das lavouras, dos engenhos, de servir como transporte de cana e de lenha, de força motriz para as moendas mais simples e alimento para a população, através dela que, partindo do litoral, foi empurrada para o interior com a expansão da cana, iniciando, assim, a ocupação do sertão. Mais tarde, a criação de gado se estendeu para o Sul, acompanhando o curso do rio São Francisco até atingir a região de Minas Gerais e, para o Norte, alcançando os chapadões do Piauí, multiplicando fazendas de gado às margens do rio Parnaíba. Junto de uma sociedade feita de açúcar e escravos, desenvolveu-se, no sertão, uma "civilização do couro", feita de gado e homens livres (trabalhadores livres em regime de parceria, como o vaqueiro ou os assalariados), conforme aponta Ferlini (1994).

Nesse quadro, ainda segundo Ferlini, a produção de alimentos para a subsistência dependia de lavradores de roça, que plantavam para seu consumo e abasteciam os mercados locais com os excedentes. Como a cana ocupava as melhores terras e atraía a todos, a Colônia sofria constantemente com a falta de alimentos e os preços altos. Ademais, era preciso alimentar os escravos, o que era feito através da mandioca, sendo estabelecido pela legislação da Colônia que os plantadores de cana deveriam reservar terras e tempo para que os próprios escravos plantassem esse produto.

O exposto acima mostra-nos a existência de um campesinato no país, desde a primeira forma de exploração mercantil na agricultura - a cana-de-açúcar. Ratificando isso, Manuel Correia da Andrade (1995) afirma que desde o período colonial, passando 
pelo Brasil-Império, já se encontrava um germe de campesinato em torno da classe senhorial e se sobrepondo aos escravos.

Alberto Passos Guimarães (1989) afirma que no início do século XVIII, quando a população da Colônia já havia ultrapassado um milhão de pessoas, tanto a agricultura de subsistência quanto a agricultura de exportação já estava em crise, e se agravou ainda mais com o surto da mineração de ouro e diamante em Minas Gerais, o qual desencadeou várias correntes migratórias de escravos e homens livres. A mineração fez implantar pelas áreas próximas, lavouras de milho e outros gêneros de subsistência, proporcionou criatórios de animais, atraiu gados de maior e de menor porte, além de artigos de consumo necessários e supérfluos, produzidos aqui e no além-mar.

Vários estudiosos reduziram o papel da agropecuária diante da economia mineradora que se desenvolveu em Minas Gerais a partir do final do século XVII. Apontam apenas a existência local de uma pequena "economia de subsistência", sem maiores dimensões, subsidiária da atividade mineradora exportadora e com baixa produtividade e rendimento. Para esses autores, a agricultura só viria a ter uma maior importância após a decadência da mineração (MULS, 1990).

Autores da historiografia brasileira mais recente têm refutado essa tese e têm mostrado, como expõem Guimarães e Reis (1986, p. 34), que, por um lado, se a agricultura foi considerada uma atividade subsidiária da economia mineradora, por outro, a permanência da empresa mineradora foi graças à sustentação dada pela atividade agrícola. "Se a mineração está na gênese da agricultura, esta por sua vez se constitui em base de preservação da atividade mineradora".

Muls (1990), por sua vez, é mais enfática ao defender que era muito mais racional para os mineradores e comerciantes comprarem os bois, os cavalos, as mulas, o peixe e o sal nas regiões vizinhas do sertão de São Francisco do que das regiões de Curitiba, do Rio Grande do Sul ou do Uruguai; poderiam comprar ainda o milho, o açúcar, a rapadura, a aguardente, a carne de porco e o toucinho das regiões mais próximas às minas do que adquiri-los por preços absurdos dos tropeiros e demais mercadores que vinham do Rio de Janeiro ou de São Paulo. Seria melhor ainda, como já demonstraram Guimarães e Reis, que eles próprios produzissem todos esses bens.

A decadência da produção aurífera, iniciada na década de 1730, vai levar ao deslocamento dos mineradores e ao povoamento de outras regiões, via agricultura e 
pecuária.

Contudo, notamos que a atividade mercantil desenvolvida em Minas Gerais, apesar de ser distinta daquela que ocorreu primeiro no Nordeste, fundada na economia agroexportadora do açúcar, não guardou muitas diferenças em relação aos interesses da metrópole. O ponto diferente é que em um local o produto principal foi baseado na agricultura, o açúcar, e em outro, foi a exploração mineral de ouro e diamante.

Vários são os pontos comuns: primeiro, ambas as economias mercantis, se fundam na grande propriedade da terra, instituída pelas sesmarias, e no trabalho escravo. Em segundo lugar, mas não menos importante, desde o início, há uma coexistência da pequena propriedade, geralmente baseada na posse da terra, associada à economia camponesa gerada pelo trabalho livre e pelo próprio trabalho escravo, que se apresentava tanto no interior dos latifúndios de forma agregada ao grande proprietário, ou nas áreas chamadas de "franjas" das sesmarias, quanto também em locais mais distantes dos latifúndios e da mineração (como as grotas distantes, por exemplo). O gado também, mesmo não estando vinculado à economia mercantil, constituiu-se numa importante forma de interiorizar a ocupação dos ditos "sertões" e, principalmente, é o caminho aberto pelo gado, do sertão nordestino às minas, que vai favorecer mais tarde a circulação de pessoas e gêneros de consumo entre as regiões, bem como ainda é o gado no curso do rio São Francisco que proporciona a ocupação das áreas, inclusive do Norte de Minas Gerais. A ocupação desta região, por sua vez, não será em consequência da mineração, mas sim do gado. O Norte de Minas Gerais que vai auxiliar no abastecimento da região mineradora.

Dessa forma, segundo Costa (2007), Minas Gerais é fruto da combinação da sociedade mineradora, nas entranhas da Serra do Espinhaço, com a sociedade pastoril, disseminada pelas chapadas ao longo do médio curso do São Francisco. Este mesmo autor, citando o historiador paulista Affonso de Taunay (1948), afirma que por volta do ano de 1612, algumas bandeiras anônimas paulistas começaram a percorrer o rio São Francisco formando, mais tarde, o chamado Caminho Geral do Sertão.

Para Ribeiro (2005), a conquista do Sertão Mineiro, nesse contexto, é disputada por paulistas e baianos que partiram de direções opostas e se encontraram no chão norte mineiro, onde estabeleceram as fazendas de gado que transformaram o São Francisco no "rio dos currais". Costa (2007) aponta para o fato de que na década de 1650, a sociedade 
do Recôncavo Baiano começou a ser invadida por grupos indígenas aliados a negros aquilombados no sertão, sendo que as expedições baianas não foram capazes de eliminar essas ameaças sobre as populações dedicadas à produção de açúcar. Daí, o governo da Capitania da Bahia pediu auxílio a paulistas, entre eles, veio Mathias Cardoso de Almeida, que comandava a bandeira herdada de seu pai, junto com um grupo de mais de cem bandeirantes, além de escravos negros e indígenas para a região do médio rio São Francisco, os quais tinham como objetivo capturar índios e acabar com os quilombos que ameaçavam as povoações dedicadas ao cultivo da cana-deaçúcar e à criação de gado.

\begin{abstract}
Ao chegar, por volta de 1660 na região do rio Verde Grande, Mathias Cardoso de Almeida e seu grupo aí se estabeleceu. Foram fundados alguns arraiais e algumas fazendas, dentre eles, o Arraial do Meio ou de Mathias Cardoso e a fazenda Jahyba de Antônio Gonçalves Figueira nas cabeceiras do rio das Rãs, próxima a Bom Jesus da Lapa na Bahia. Entretanto, pouco depois de estabelecidos os arraiais nas margens do rio Verde Grande, tiveram que mudar suas localizações devido às inundações e à insalubridade da área. Fundou-se então, nas margens do rio São Francisco e amparado por algumas elevações rochosas, o povoado de Morrinhos, hoje cidade de Matias Cardoso. Essa a primeira povoação duradoura a se estabelecer no território mineiro, apesar de na época pertencer à Capitania da Bahia (COSTA, 2007, p. 31-32).
\end{abstract}

O autor supracitado ainda afirma que a bandeira de Mathias Cardoso de Almeida foi chamada para retornar a São Paulo e acompanhar Fernão Dias Paes na busca das esmeraldas. Nesse momento, em 1668, fundou ainda as povoações de Brejo do Salgado, hoje Januária, e São Romão. Foi desde essa época que a sociedade pastoril disseminada a partir de Morrinhos (hoje município de Matias Cardoso) se dedicou à criação de gado e de gêneros alimentícios, que comercializavam com a cidade de Salvador e o Recôncavo. O comércio entre os dois lugares, denominado caminhos do sertão ou caminhos da Bahia, foi tão intenso que possibilitou à população de Morrinhos a construir uma grande igreja, a primeira de Minas Gerais, dedicada a Nossa Senhora da Conceição. Fato este ocorrido em 1695, poucos meses antes da fundação do Arraial de Nossa Senhora do Carmo, hoje Mariana, que ocorreu em julho de 1696 (COSTA, 2007).

Por esse motivo, Matias Cardoso tem reclamado o papel simbólico de berço dos Gerais, já que a Mariana foi consagrado o título de berço de Minas. Assim sendo, voltamos a reafirmar que a sociedade norte mineira não é fruto da mineração, mas sim, fruto do gado que se afirma e consolida a ocupação e o povoamento do território, que, 
em seguida, forma um campesinato particular, o do sertão. Isso, a nosso ver, corrobora com a assertiva de Ribeiro (2005, p. 192), quando ele afirma que "a ocupação do vale do São Francisco por fazendas de gado, no entanto, não deve ser atribuída apenas aos potentados paulistas ou baianos, mas parece também ter sido obra de anônimos homens pobres que iam se dispersando pelo sertão e ali se fixando".

\section{O campesinato sertanejo nos Gerais}

O campesinato do sertão mineiro praticamente ficou esquecido em detrimento de todo o destaque dado à atividade mineradora. Os registros que aparecem com maior freqüência com relação ao campesinato em Minas Gerais nos períodos colonial e imperial mostram uma pequena agricultura ao redor da atividade mineradora, incipiente e sempre subordinada, conforme já mostramos acima, mas também procuramos apontar as incoerências desse discurso contraditório. A mineração foi, sem dúvida, subsidiada pela agricultura e pecuária que se desenvolveram nos arredores das minas, bem como pelo abastecimento de alimentos que vinham do sertão, de outras regiões do estado e das mercadorias trazidas pelas tropas de São Paulo, do Rio de Janeiro e do sul do país.

O campesinato sertanejo foi e é praticamente esquecido na história de Minas Gerais, mas é uma forma singular de apropriação e uso dos recursos naturais do sertão. A formação do estado de Minas Gerais é contraditória e visivelmente dual, desconsiderando a importância do sertão mineiro na sua história. A própria construção da mineiridade é usada para reforçar a negação do sertanejo como identidade territorial do estado. Segundo Costa (2007), no processo de construção da mineiridade, nas primeiras décadas do século passado, que trata Sylvio Vasconcellos (1968), a região dos Gerais foi obliterada para enfatizar o papel da região das Minas. Para este autor, era preciso chamar "a atenção para a possível especificidade de uma região brasileira, contida nos precisos limites da ocupação humana condicionada pelo ouro, não ampliada às fronteiras do território que se chamou Minas Gerais. Isto porque, ao que parece, as Minas diversificam-se das Gerais" (VASCONCELOS, 1968, p. 7 apud COSTA, 2007, p. 24) (Grifos no material reproduzido).

Se por um lado temos a mineiridade como identidade das Minas, pelo outro a sertanidade é a identidade dos gerais. O campesinato sertanejo é formado dessa 
oposição; um campesinato que se formou no sertão mineiro independente da região mineradora, ligado ao pastoreio e às diversas formas de uso e apropriação dos recursos naturais dos Cerrados.

Estamos falando de um campesinato sertanejo que se manifesta de várias maneiras pelos Cerrados, nas vazantes e nas chapadas, nas grotas e nos tabuleiros, nas veredas, nos cerrados e nos cerradões, nas matas secas e nas caatingas. O campesinato sertanejo congrega também diversos grupos sociais de acordo com a sua vinculação com os recursos naturais e com os ambientes em que se encontram: vazanteiros, barranqueiros, chapadeiros, cerradeiros, geraizeiros, veredeiros, caatingueiros, extrativistas, quilombolas, índios, camponeses, quebradeiras de coco, podendo incluir ainda os artesãos que vivem do extrativismo de palhas, castanhas etc., ou da extração de argilas para confeccionar peças de decoração e utensílios domésticos, como é o caso das artesãs do Vale do Jequitinhonha. Estamos falando ainda de um campesinato sertanejo cuja marca é a diversidade: a diversidade de povos, de modos de vida, de ambientes (ecossistemas), de relações específicas com os recursos naturais, mas que também guarda valores sociais, ecológicos, culturais e espirituais.

O campesinato sertanejo é aquele que extrai indiretamente da terra tudo o que nela se produz, que foi plantado, cultivado e colhido pelo camponês; e também extrai diretamente da terra o que ela produz: o pequi, o panã, a mangaba, a cagaita, o jatobá, o buriti etc.

O campesinato sertanejo é um valor, ou melhor, são valores. São valores que se expressam em diferentes tempos e lugares, de modo semelhante ao que Woortmann (1990) considerou como uma "qualidade", se referindo à campesinidade. É o valor que se manifesta nas práticas de cultivo da terra; o valor presente nas relações com a natureza, na reciprocidade e no respeito que o camponês tem para com os recursos naturais que extrai; os valores éticos e morais cultuados no interior e fora da família; é o valor que se encontra no respeito e na gratidão ao sagrado; são valores de solidariedade e reciprocidade para com a sua comunidade; é o valor que o alimento tem para a família camponesa.

Existe uma diversidade de formas camponesas e de sujeitos que vivem produzindo em conciliação com os recursos naturais, o campesinato sertanejo é uma delas. Nesse sentido, Shanin (2005) afirma que as condições de vida camponesa necessitam e se 
moldam pelo estabelecimento de um "eco-sistema" e um equilíbrio entre agricultura, extrativismo e artesanato, com uma ênfase particular no cultivo. No campesinato, e isso foi possível verificar também durante a pesquisa de campo, a base principal é a agricultura, ou melhor, são as atividades agropecuárias. Ainda que nos territórios estudados haja uma importante ênfase no extrativismo, principalmente do pequi, o cultivo agrícola e a criação de animais são as atividades mais importantes, pois além do fato de serem estes que vão garantir a alimentação da família, eles também são atividades constantes no dia a dia camponês. O extrativismo normalmente é sazonal, mas o artesanato, mesmo sua produção sendo permanente, ainda assim o fluxo de venda é variável. Por isso, a maioria dos estudos sobre o campesinato concentra suas análises nas atividades de cultivo e criação. As demais atividades exercidas pela família camponesa, mesmo gerando renda maior que a agropecuária, sempre serão complementares. A atividade principal dos camponeses é o cultivo e a criação, porque é a partir dela que eles se definem enquanto tal.

O uso que o campesinato sertanejo faz dos recursos naturais construiu uma relação histórica e cultural, gerando vários saberes que atravessam gerações, pois o camponês vive e percebe cada mudança que ocorre na natureza. Para o camponês do sertão (e também os outros camponeses), as mudanças na natureza e o ciclo de cada um dos recursos naturais não estão marcados em um calendário; cada planta tem seu tempo de cair as folhas, brotar, embotoar (para aquelas plantas que soltam "botões", antes das flores), florir, nascer o fruto e amadurecer. Através disso o camponês vai percebendo a mudança do tempo. Ao perguntar para um camponês do sertão, por exemplo, em que época ou mês o pequi começa a amadurecer, mesmo que ele não saiba- uma resposta muito improvável-, ele irá associar o "tempo" do pequi ao de outra fruta ou mesmo ao período das chuvas e irá responder.

\section{O pequi e os saberes locais dos camponeses do sertão}

O território que compreende o campesinato sertanejo é marcado por uma diversidade que envolve modos específicos de viver nos ambientes, ou como diria Shanin nos "eco-sistemas", inseridos. Nesse modo de vida, o campesinato estabelece práticas e valores que se desenvolvem histórica e culturalmente no território, os quais 
são transmitidos pelo parentesco, pela vizinhança e pelas relações comunitárias. Ao longo do tempo, o campesinato foi, e ainda continua, "cultivando" saberes os quais são fundamentais à sua manutenção e existência enquanto um modo de vida que resiste às transformações socioeconômicas e espaciais da sociedade como um todo. Saberes estes que se materializam em relação à natureza, pelo seu conhecimento sobre os mecanismos que movem-na; saberes acumulados, desenvolvidos e recriados a partir das técnicas de cultivo; saberes enquanto valores sociais indispensáveis à família e à convivência comunitária; os saberes sobre os usos dos recursos naturais para a geração de renda, para a alimentação e uso medicinal etc. Os saberes do camponês são muito maiores do que a experiência de uma vida longa, pois às vezes encontramos sujeitos relativamente jovens que possuem experiências e vivências que parecem ser de uma vida toda.

Para Diegues e Arruda (2001, p. 31), o conhecimento tradicional pode ser definido "como o conjunto de saberes e saber-fazer a respeito do mundo natural e sobrenatural, transmitido, oralmente, de geração em geração". Assim, podemos exemplificar os cuidados que os camponeses sertanejos dispensam ao pequizeiro e a todo o imaginário: as crendices, os costumes e usos em torno do fruto rei do Cerrado, formando esse conjunto de saberes tradicionais, além do saber-fazer o óleo de pequi e as receitas com o fruto da culinária sertaneja.

Nesse contexto, concordamos com Muñoz (2003, p. 294-295) quando ela analisa a vida dos povos indígenas e afirma que o saber é cotidiano, porque, além de técnicas e conhecimentos, ele também envolve a pessoa e o seu meio, a natureza, a vida vegetal e animal. Por isso, consoante a autora, "o saber cotidiano dá conta dos conhecimentos que a pessoa integra e daqueles que circulam no seu mundo de vida e que, segundo a maneira própria de compreender e interpretar, adaptam-se em saber ser e fazer com sentido comum" (grifos da autora).

Embora cada indivíduo tenha um modo particular de ver o mundo e as coisas, os saberes entre grupos tradicionais, como os camponeses sertanejos, em geral, são sempre comunitários. O saber comunitário se reproduz em forma oral e, por isso, se constitui num importante acervo da história viva de um grupo ou uma comunidade.

Os saberes tradicionais, geralmente mais próximos da relação do homem com a natureza não podem ser analisados ou comparados ao fazer moderno, tampouco ser considerados inferiores em detrimento do uso de formas técnicas superiores. Os saberes 
tradicionais são sempre singulares. O saber-fazer o óleo de pequi se torna um exemplo de que o "tradicional" também guarda suas especificidades, possui seu valor, e nem por isso é menos moderno.

O campesinato sertanejo é também um modo de vida baseado nos sabores que o sertão oferece. Os Cerrados são riquíssimos em biodiversidade, principalmente de origem vegetal. São vários frutos disponíveis nos Cerrados que são utilizados pelos camponeses para se alimentarem e, dependendo da circulação, oferecem possibilidades de ganhos econômicos que complementam a renda de suas famílias, além de que, dentre alguns frutos, já são conhecidas há muito tempo pelos camponeses e reconhecidas pela medicina natural, as suas propriedades medicinais.

Indubitavelmente, o pequi e sua árvore, o pequizeiro, são o fruto e a espécie mais conhecidos dos Cerrados Brasileiros, não apenas pela sua reconhecida apreciação alimentícia, mas pelo conjunto de valores que eles representam para as populações: econômico, cultural, ecológico, gastronômico e medicinal. Assim, no que se refere ao pequi e ao pequizeiro, concordamos com Dematteis $(2007$, p. 10) quando ele afirma que por valores "não entendemos somente os valores de mercado, mas também e sobretudo, os recursos ecológicos, humanos, cognitivos, simbólicos, culturais que cada território pode oferecer como valores de uso, bens comuns, patrimônio da humanidade".

Vamos tratar daquilo que Ellen Woortmann (2004) se referiu como o "triângulo Deus-homem-terra" para demonstrar como o pequi e o pequizeiro estão sacramentados no campesinato sertanejo. Os relatos de vários camponeses, os quais vamos reproduzir, nos mostram os valores do fruto e da árvore símbolos dos Cerrados na vivência deles. São demonstrações de respeito e reciprocidade à natureza, ao sagrado e aos saberes cultivados entre aqueles que observam as pequenas manifestações da grandeza da natureza.

É o pequi que promove a "riqueza" das pessoas, mas uma riqueza que não se manifesta pelo princípio da acumulação; é a riqueza que está no pequi que alimenta, que é comercializado e retorna para a casa sob a forma de alimento, de remédios ou de outros bens que a família camponesa necessita. O pequi é o "ouro do Cerrado", conforme regionalmente é conhecido no Norte de Minas Gerais, tanto pela sua cor amarelada quanto pela renda que oferece aos sertanejos do campo e da cidade.

A crença de que a natureza é obra do sagrado é uma constância na vida 
camponesa, "porque o pequi ajuda a pobreza demais, abaixo de Deus" (camponês, 60 anos, Japonvar). Ou então, "abaixo de Deus aqui nas águas é o pequi, para nós aqui" (camponês, 68 anos, Japonvar). O pequi é a riqueza que ajuda os "pobres" do sertão; se Deus manda a chuva, que é a época na qual não há produção para o camponês, Ele também manda o pequi para substituir a falta da colheita da lavoura. "A riqueza nossa aqui, dos pobres aqui, é o pequi" (camponesa, 42 anos, Japonvar).

De acordo com Moura (1986), o peso específico da religião, ou também podemos nos referir como o peso da fé ou da crença, é maior na cultura simbólica camponesa, por ser a fé fornecedora de respostas e de uma explicação cheia de sentidos e sinais para quem observa diariamente o mistério da terra, da água e do ar, enfim, da natureza e dos mistérios divinos.

O pequi, semelhantemente a outros frutos nativos dos Cerrados, é coletivo, porque, na concepção do camponês do sertão, ele não foi plantado por ele. O pequi preexiste ao camponês: "já é nativo, é uma coisa que vem de tempos em tempos; pequi pra nós aqui é tudo; é festa quando é tempo de pequi neste lugar" (camponês, 25 anos, Japonvar). A própria idéia de que não foi feito esforço para plantar, cuidar e colher, como ocorre na lavoura, retira o peso do significado do trabalho do camponês: "é uma coisa que Deus deu lá no mato, ninguém plantou" (camponesa, 42 anos, Minas Novas). Por isso, o pequi pode ser compartilhado, mas com restrições: "Deus deixou pequi para todo mundo, só não aceito derrubar" (camponês, 68 anos, Japonvar).

As restrições colocadas pelo camponês do sertão ao outro que também coleta o pequi é devido a ele entender que o fruto só está totalmente maduro quando cai no chão. $\mathrm{O}$ respeito e o cuidado para com aquilo que a natureza lhe oferece é condição fundamental ao camponês: "quando a gente limpa eles [os pequizeiros], parece que eles gostam mais, dão mais". "No meio do mato, eles morrem, tem muitos galhos" (camponês, 64 anos, Japonvar).

Assim sendo, os camponeses se empenham em cuidar do pequizeiro, pois já perceberam que, quando eles roçam o mato embaixo da árvore, ela dá mais fruto e com uma qualidade melhor. A natureza e o pequizeiro, agradecidos, retribuem-lhes com bons frutos. É a reciprocidade entre homem e natureza. Todavia, a natureza de Deus, conforme ressalta Woortmann (2004), também castiga o homem, porque isso depende de sua conduta, a qual, com freqüência, afronta a vontade divina: "tem gente que vem 
de longe e quer que panham no pé, mas ninguém pega. Se bater vara no pequizeiro, no outro ano não dá. Coisa que é da natureza" (camponesa, 42 anos, Minas Novas). Para aquele que maltrata o pequizeiro e vai numa direção contrária à lei que a natureza dita, catar o pequi do chão, ocorre o que a camponesa de 49 anos, de Cabeceiras do Mangaí, em Japonvar, afirma: "é praga, porque de primeiro o povo não tirava os pequis. Quebram os galhos e no outro ano dá menos".

Para um camponês de Campo Azul, quem retira o pequi verde infringe duas leis - uma legal e outra divina: "é proibido tirar verde, o IBAMA multa e prende o carro; é um pecado também enganar as pessoas" (camponês, 50 anos, Campo Azul).

A dualidade é outro ponto que aparece muito forte também nas relações do camponês com a natureza. Os opostos quente/frio, seco/úmido, forte/fraco, entre outros, estão claramente presentes na natureza de forma a equilibrá-la ou harmonizá-la e não deixa de ser diferente entre os humanos. De acordo com Woortmann (2004, p. 135), "tudo, na natureza de Deus, ou é quente ou é frio", incluindo também a oposição "seco" e "úmido".

Com o pequi, também não é diferente. A oposição quente e frio, forte e fraco é bem destacada entre as pessoas que conhecem o fruto e se alimentam dele, além de permear a crendice popular. Nesse sentido, destacamos algumas falas dos entrevistados que ratificam isso:

\footnotetext{
"Pequi é forte. É quente. Se comer muito faz mal, se comer com uma carne de porco..." (camponês, 64 anos, Japonvar). "Pequi é reimoso, sai perebas" (camponês, 45 anos, Campo Azul). "Pequi é quente. É quente pro sangue. No tempo do pequi sai feridas no corpo. Altera o sangue. Mulher que come rende menino. É quente. Que o homem também fica meio furioso" (camponês, 77 anos, Japonvar). "O povo fala: arranjei menino foi na força do pequi" (camponesa, 28 anos, Campo Azul).
}

Relatos como esses são muito comuns na região norte mineira, tanto no urbano quanto no rural, os quais foram registrados durante nossa pesquisa com os camponeses do sertão. É interessante destacarmos que, embora algumas famílias entrevistadas nas comunidades rurais Cachoeira do Fanado e Cachoeira da Lagoa, em Minas Novas, reconheçam as propriedades medicinais do pequi, a exemplo de sua função expectorante, elas desconhecem a crendice popular que afirma sê-lo afrodisíaco, além de favorecer a fertilidade feminina. Em um trabalho mais antigo tal questão já havia 
sido destacada por Sampaio (1944, p. 49), citando um artigo publicado por Otacílio Lisboa (1941), na qual o autor faz referência ao pequi no Norte de Minas Gerais, mais especificamente na região do Alto Rio Pardo, em que nos sertões onde se faz

\begin{abstract}
uso constante do fruto ou do óleo de piqui, os habitantes são sadios e fortes, de péle corada e macia, alem de possuírem grande energia fecundante; e que é muito conhecido nos sertões brasileos o fenomeno da enorme procreação das mulheres, nas quadras em que há grande abundância de piqui.
\end{abstract}

De acordo com o nosso entrevistado mais velho em Japonvar, 85 anos, "o ano que dá muito pequi é o ano que tem mais menino".

Se o pequi é um alimento quente e forte, fica claro nas falas dos camponeses do sertão que a mistura dele com outro alimento quente e forte, como a carne de porco, pode levar a uma indigestão. Mas, não é só em volta do pequi que circula esse tipo de saber popular, outros frutos dos Cerrados também.

O saber tradicional camponês é vasto. Outros saberes foram destacados durante a pesquisa, como a sabedoria de uma camponesa de Japonvar. Ela costuma passar óleo de pequi no feijão para poder armazenar, por o óleo proteger o feijão contra a ação de carunchos.

O pequi, por outro lado, já ajudou muito as pessoas dos territórios rurais entrevistados em Minas Novas, inclusive como fonte de energia, pois, consoante lembra uma jovem camponesa, o óleo de pequi substituía o querosene para iluminar quando ainda não havia luz. Ou então, o camponês "antigamente fazia um pavio de algodão e molhava com óleo de pequi e acendia, quando ainda não tinha luz..." (camponês, 70 anos, Guarda Mor, Campo Azul).

As outras partes do pequi também apresentam diversos usos segundo os camponeses. A castanha ou amêndoa é usada para doce, paçoca, ou dela é retirado o óleo. A casca do pequi serve de adubo para a plantação ou para alimentar criações como gado e porco; a folha do pequi serve para fazer chá para indigestão, problemas estomacais e para o fígado. Existem estudos atestando que a folha do pequi é adstringente.

Sobre o pequizeiro e a flor do pequi, perguntamos ao camponês se a seca atrapalha a produção do fruto, ele respondeu: "não, o pequi não faz muita parte [da seca], e de água também não. Só se chover muito na flor, perde o pequi. A chuva tira o 
mel da flor que vai formar o pequi" (camponês, 33 anos, Japonvar). Segundo os agricultores do Norte de Minas Gerais, o gado aprecia muito a flor do pequi, que nessa época chega a perder peso devido não comer pastagem nem beber água. Além disso, ressaltam os camponeses que a vaca pode abortar o bezerro se comer muita flor de pequi, além de causar diarréia no gado.

A identificação do camponês sertanejo com o pequi pode ser representada pela fala de um camponês da comunidade rural Cachoeira da Lagoa, em Minas Novas: "é bão, Deus o livre se acabar o pequi. Eu mesmo adoro o pé de pequi. Dá janeiro, eu já começo a olhar os pequis".

Conforme o camponês acima citou o mês de início da safra de pequi em sua comunidade rural, aproveitamos para apresentar um quadro/calendário que expõe os períodos de floração e maturação do fruto nas localidades onde realizamos nossa pesquisa, mencionando os três municípios em questão.

Quadro 1 - Calendário de floração e safra do pequi em municípios do Norte de Minas Gerais e Alto Vale Jequitinhonha. Levantamento pautado na percepção dos camponeses do sertão e na sua relação com o pequi no Cerrado.

\begin{tabular}{|l|c|c|c|}
\hline \multicolumn{1}{|c|}{ Município } & $\begin{array}{c}\text { Floração do } \\
\text { pequizeiro }\end{array}$ & $\begin{array}{c}\text { Início da safra do } \\
\text { pequi }\end{array}$ & $\begin{array}{c}\text { Fim da safra do } \\
\text { pequi }\end{array}$ \\
\hline Campo Azul & Agosto/Setembro & Dezembro/Janeiro & Fevereiro/Março \\
\hline Japonvar & Agosto/Setembro & Novembro & Fevereiro \\
\hline Minas Novas & Setembro/Outubro & Dezembro/Janeiro & Março/Abril \\
\hline
\end{tabular}

Fonte: Trabalho de Campo realizado entre julho de 2009 e julho de 2010.

Constatamos que, nos dois municípios do Norte de Minas Gerais, o período de floração do pequizeiro inicia-se no mês de agosto e vai até o mês de setembro, sendo que a época da safra em Campo Azul começa entre dezembro e janeiro, mais precisamente na segunda quinzena de dezembro, e termina no início do mês de março. Já em Japonvar, é na segunda quinzena de novembro que começa a safra do fruto e encerra-se no mês de fevereiro. Em Minas Novas, no Alto Vale Jequitinhonha, a floração do pequizeiro é um pouco mais tarde, entre os meses de setembro e outubro, enquanto a safra começa no final de dezembro, podendo terminar no início do mês de abril. Vale destacar também quanto à safra, que seu auge se dá exatamente na metade do 
período, uma vez que, normalmente, temos três meses (ou um pouco mais de tempo) de safra de pequi.

O período da safra destacado aqui pode variar geralmente no início ou no final da safra, porque, de acordo com o que foi destacado pelos camponeses, o pequizeiro não produz todo ano de forma igualitária, há ano que a produção é grande e outro em que diminui sensivelmente. Acreditamos que tal fato pode estar ligado à questão biológica da planta ou até mesmo relacionado com questões climáticas. Por exemplo, se depois do período de floração não chover para que o fruto se desenvolva, costuma-se perder muito pequi, daí a produção cai bruscamente e o período de safra termina mais cedo.

Do ponto de vista cultural, o pequi tem significado importante para os camponeses e ajudam a construir a sua territorialidade. É muito comum encontrarmos camponeses cheios de orgulho para destacar a valorização do seu pequi: "dizem que o melhor pequi que tem é o da região de Campo Azul" (camponês, 45 anos, Campo Azul); “em ritmo de vegetação natural mesmo, o que tem mais valor é o pequi. É considerado o melhor pequi para o pessoal aí de fora" (camponês, 42 anos, Campo Azul); "todo mundo procura pequi de Campo Azul. No tempo, ajuda todo mundo. Nas festas, o pessoal tá levando para fazer propaganda. Campo Azul pegou fama com o negócio do pequi" (camponês, 60 anos, Campo Azul).

O pequi de Campo Azul tem tal valor pelo fato de ser um fruto maior, mais carnudo e com sabor mais acentuado, o que faz ele ter uma excelente aceitação no mercado, especialmente no estado de Goiás. O pequi está simbolicamente representado no cotidiano das pessoas, pois "eles fizeram umas folhinhas [calendários] aí e tinham o pequi" (camponesa, 28 anos, Campo Azul). Mas, em termos de marketing, sem dúvida, é o pequi da região de Japonvar que se destaca do Norte de Minas Gerais para o Brasil, pelo fato de ser um dos municípios pioneiros no extrativismo e na transformação agroindustrial do fruto, o que rende créditos aos camponeses desta localidade. Essa última fala resume a importância do pequi em Japonvar: "Pequi é falado. Toda Minas Gerais. Todo Brasil. Japonvar, capital nacional do Pequi!” (camponesa, 49 anos, Japonvar). 


\section{Considerações Finais}

Trouxemos uma pequena parte da fundamentação teórica conciliada com o universo empírico de nossa pesquisa de mestrado que se encontrava em elaboração até o período de realização do SINBIOTEK, a qual nos revela ser a vida camponesa, especialmente no sertão, construída através de um vasto saber popular em comunhão com a apropriação e o uso dos recursos naturais disponíveis no território sertanejo do Norte de Minas e do Vale do Jequitinhonha - os Cerrados.

Dessa forma, estamos tentando abrir caminhos para uma conciliação mais harmoniosa entre saberes locais e/ou tradicionais com o conhecimento científico. Talvez a ciência contemporânea tenha caminhado no sentido de se aproximar mais dos saberes tradicionais, o que não fez ou vinha fazendo de forma muita lenta até poucos anos. Inúmeras são as experiências bem sucedidas, principalmente nos campos da alimentação, da farmacologia, dos cosméticos, entre outros, que transformaram os recursos naturais dos Cerrados em medicamentos ou novos produtos, baseados inclusive nos saberes de populações tradicionais, como a indígena e os camponeses.

Com o pequi, não pode ser diferente. Já algum tempo diversos estudos têm sido publicados revelando propriedades farmacológicas e nutricionais do fruto símbolo dos Cerrados brasileiros. Como adubo, ração, na alimentação e nas suas várias utilidades, o pequi deixa um leque de possibilidades para que se invista nas suas potencialidades econômica, farmacológica, nutricional, ecológica, cultural e social, sendo que é de fundamental importância considerar os múltiplos saberes que podem ser apreendidos com os camponeses sertanejos.

Colocamos aqui apenas apontamentos que possam permitir reflexões acerca do pequi e dos saberes camponeses, sendo que estas considerações finais não obedecem ao rigor do tradicionalismo acadêmico de um artigo.

\section{Referências}

ANDRADE, Manuel Correia de. A questão do território no Brasil. São Paulo-Recife: Hucitec-IPESPE, 1995. 135 p. 
COSTA, João Batista. Movimento Catrumano: o Norte de Minas como berço de Minas Gerais. Revista Verde Grande, Montes Claros, v. 1, n. 4, p. 24-36, nov./dez. 2007.

DEMATTEIS, Giuseppe. Apresentação - O território: uma oportunidade para repensar a Geografia. In: SAQUET, Marcos Aurélio. Abordagens e concepções de território. São Paulo: Expressão Popular, 2007. p. 7-11.

DIEGUES, A. C.; ARRUDA, R. S. V. (Org.). Saberes tradicionais e biodiversidade no Brasil. Brasília: Ministério do Meio Ambiente, 2001. (Série Biodiversidade; 4).

FERLINI, Vera Lúcia Amaral. A civilização do açúcar: séculos XVI a XVIII. 9. ed. São Paulo: Brasiliense, 1994. 100 p. (Tudo é história; 88).

GORENDER, Jacob. Gênese e desenvolvimento do capitalismo no campo brasileiro. In: STÉDILE, J. P. (Org.). A questão agrária hoje. Porto Alegre: Ed. da Universidade/ UFRGS, 1994. p. 15-44.

GUIMARÃES, Alberto Passos. Quatro séculos de latifúndio. 6. ed. Rio de Janeiro: Paz e Terra, 1989. 255 p. (Estudos brasileiros; 24).

GUIMARÃES, Carlos Magno; REIS, Liana Maria. Agricultura e escravidão em Minas Gerais (1700/1750). Revista do Departamento de História da UFMG, Belo Horizonte, v. 1, n. 2, p. 7-36, jun. 1986.

KAUTSKY, Karl. A questão agrária. Porto: Portucalense, 1972.

MOURA, Margarida Maria. Camponeses. São Paulo: Ática, 1986. 78 p. (Série Princípios).

MULS, Nair Costa. A formação da estrutura agrária mineira e a gênese do campesinato. Análise \& Conjuntura, Belo Horizonte, v. 5, n. 3, p. 94-109, set./dez. 1990.

MUÑOZ, Maritza Gómez. Saber indígena e meio ambiente: experiências de aprendizagem comunitária. In: LEFF, Enrique. (Coord.). A complexidade ambiental. São Paulo: Cortez, 2003. p. 282-322.

RIBEIRO, Ricardo Ferreira. Florestas anãs do Sertão - o Cerrado na História de Minas Gerais. Belo Horizonte: Autêntica, 2005. 480 p. v. 1.

SAMPAIO, A. J. de. A alimentação sertaneja e do interior da Amazônia: onomastica da alimentação rural. Rio de Janeiro: Companhia Editora Nacional, 1944.

SHANIN, Teodor. A definição de camponês: conceituações e desconceituações - o velho e o novo em uma discussão marxista. Revista NERA, Presidente Prudente, v. 8, n. 7, p. 1-21, jul./dez. 2005.

WOORTMANN, Ellen F. O saber tradicional camponês e inovações. In: OLIVEIRA, A. U.; MARQUES, M. I. M. (Org.). O campo no século XXI: território de vida, de luta e 
de construção da justiça social. São Paulo: Ed. Casa Amarela/ Paz e Terra, 2004. p. 133143.

WOORTMANN, Klaas. "Com parente não se neguceia": o campesinato como ordem moral. Anuário Antropológico, Brasília: Edunb; Rio de Janeiro: Tempo Brasileiro, n. 87, p. 11-73, 1990.

Recebido para publicação em novembro de 2011 Aprovado para publicação em outubro de 2012 